\title{
Outcome of Infragenicular Prosthetic Grafts with and Without Distal Anastomotic Modification - A Retrospective Single Center Study
}

\section{Abhay Setia ( $\sim$ s.abhay0104@gmail.com )}

Darmstadt Hospital: Klinikum Darmstadt

\section{Omid Yousefi}

Department of vascular medicine, Division of vascular and Endovascular Surgery

\section{Patrick Felix Samp}

Department of Neuroradiology, Goethe-University medical center, Frankfurt am Main

\section{Peter Knez}

Klinikum Wetzlar

\section{Farzin Adili}

Depart of Vascular medicine, Division of Vascular and Endovascular Surgery, Klinikum Darmstadt

\section{Research article}

Keywords: Peripheral arterial obstructive disease, below-knee revascularization, prosthetic grafts, venous modifications of distal anastomosis, venous conduits, amputation-free survival

Posted Date: May 18th, 2021

DOI: https://doi.org/10.21203/rs.3.rs-486183/v1

License: (c) (i) This work is licensed under a Creative Commons Attribution 4.0 International License. Read Full License 


\section{Abstract}

Background: Peripheral revascularization with below-knee bypass (REBEL) utilizing prosthetic grafts demonstrate inferior patency and amputation-free survival rates, as compared to venous conduits. Because of improved hemodynamics, adding a venous modification to distal anastomoses in REBEL with prosthetic grafts is assumed to improve both patency and amputation-free survival. The aim of this study was to assess the performance of prosthetic grafts with and without venous modifications of the distal anastomosis (MOD) and compare the results with venous conduits, in terms of patency rates, amputation prevention and survival.

Methods: The present single center retrospective, non-randomized observational study involved 221 REBEL in 201 patients. Data was collected by viewing hospital records and follow-up clinical and duplex ultrasound examinations (up to 48 months). For analysis, the patients were divided in 3 groups; REBEL using prosthetic grafts with MOD (PGY) or without (PGN) anastomotic modification and REBEL using plain venous conduits without anastomotic modifications (VG). Primary patency, assisted primary patency, secondary patency, amputation-free survival and overall survival was analyzed.

Results: The median follow-up was 27 months. The most common site of distal anastomosis in PGY were the crural arteries (77.8\%) and $50 \%$ of PGY patients had already undergone vein-harvesting for peripheral revascularization. Average duration of surgery for PGY was 284 minutes, $>70$ minutes more as compared to PGN $(p=0,001)$. In PGY a statistically insignificant tendency to decreased primary and secondary patency rates as compared to PGN was observed at 12 and 36 months. PGY displayed a significant lower amputation-free survival rate at 12 and 48 months as compared to PGN $(62.9 \%$ vs $87.6 \%$ and $43.4 \%$ vs $69.75 \% ; p=0.038)$. Overall survival for the three groups was not different $(p=0.375)$.

Conclusion: To summarize, modification of the distal anastomotic site using venous cuff techniques did not result in improved patency or amputation prevention. Nonetheless, from a technical view of facilitating the creation of anastomoses between relatively rigid, large bore prosthetic grafts and calcified delicate small diameter infrapopliteal arteries, anastomotic modelling offers potential anatomic and hemodynamic advantages, thus improving outcome on long term follow up. However, prospective randomized studies are required to corroborate this hypothesis.

\section{Introduction:}

Since the first successful creation of a bypass graft for the treatment of peripheral arterial occlusive disease (PAOD) by Jean Kunlin in 1948, techniques for peripheral revascularization have come a long way (1). Notwithstanding the recent evolution and implementation of endovascular procedures and strategies calling for the first line use of interventional recanalization, surgical revascularization by means of bypass grafting still bodes its merits, particularly for complex lesions of the superficial femoral (SFA), popliteal and crural arteries (2). For revascularization of below knee arteries (REBEL), the ipsilateral greater saphenous vein (GSV) remains the conduit of choice $(3,4)$. However, prosthetic grafts still play an important role in cases where suitable autogenous veins are not available. Yet, diameter and compliance 
mismatch as well as technical difficulties to surgically connect a relatively rigid graft to a delicate, calcified, low flow crural artery pose a significant obstacle to satisfactory mid- and long-term outcome. Modelling of the distal anastomosis using various cuff-techniques was thought to simplify the surgical procedure and improve patency of alloplastic bypass grafts. Since the outcome of cuff techniques still remains unsettled, the present study was devised to assess the function of prosthetic grafts with and without modification of the distal anastomosis (MOD) as compared to the use of plain venous conduits.

\section{Materials And Methods:}

This single center, retrospective, non-randomized, observational study (approved by the ethics committee of the medical council in Hessen) was carried out in patients undergoing REBEL for the treatment of PAOD or peripheral aneurysms (PA) from April 2009 to April 2013. This retrospective analysis involved 221 REBEL in 201 patients. Patients undergoing REBEL after trauma or embolic episodes without PAOD or PA and patients with distal anastomosis proximal to the P3 Segment of the popliteal artery were excluded from the study. Hospital records were reviewed to collect the data. Follow-up was planned and performed prospectively for up to 48 Months by means of clinical examination and/or by phone and was aided by duplex examination (GE LogiQ7, GE Healthcare, USA). A written consent was obtained from all patients or their legal representatives before enrolment into the study.

The following parameters were tabulated (Microsoft Excel, Redmond, WA, USA) and analyzed: Patients' demographics, comorbidities, Fontaine and Rutherford categorization, ankle brachial index (ABI), duplex ultrasound findings, angiographic findings, intraoperative details (operative time, localization of the proximal and distal anastomosis, bypass material and diameter, location of the anastomosis and MOD if present) were recorded and tabulated (Microsoft Excel, Redmond, WA, USA). REBEL were categorized based on the type of graft and distal anastomosis modifications. The three categories were autogenous venous graft (VG), prosthetic graft without MOD (PGN) and with MOD (PGY).

Data analysis: Survival, limb salvage and patency rates were analyzed by Kaplan-Meier-survival curves with log-rank test. IBM SPSS 22.0 (Armonk, NY: IBM Corp.) was used for data analysis

\section{Results:}

The median follow-up was 27 months. In 23 patients the data records were complete for the planned follow-up. Follow-up clinical and duplex ultrasound examinations were performed in 70 patients and 84 bypass grafts. Thirty-two patients were followed up by phone. Sixty-five patients succumbed during the planned follow-up period. Eleven patients were lost to follow-up. The patients' demographics and comorbidities are illustrated in Table 1. The number of males in VG and PGN was statistically higher (Pearson-Chi2-Test; $p<0,005$ ). Age distribution was comparable in the three groups (Kruskal-Wallis-Test; $p$ $=0,271$ ). There was no significant difference in the presence of individual risk factors in the three groups. Hypertension and hyperlipidemia were the most frequently occurring risk factors. All patients underwent preoperative venous mapping with the help of duplex ultrasound. Out of 48 patients with aneurysm, 23 
were asymptomatic and 25 were symptomatic. Most of the patients presented with critical limb ischemia (rest-pain $n=44$ and tissue loss $n=146$ ). Only 8 patients underwent REBEL for lifestyle limiting claudication.

Table 1

Patients' demographics and comorbidities.

\begin{tabular}{|c|c|c|c|c|c|c|c|c|}
\hline & \multicolumn{2}{|l|}{ PGN } & \multicolumn{2}{|l|}{ PGY } & \multicolumn{2}{|l|}{ VG } & \multicolumn{2}{|l|}{ Total } \\
\hline Patients & \multicolumn{2}{|l|}{26} & \multicolumn{2}{|l|}{33} & \multicolumn{2}{|l|}{142} & \multicolumn{2}{|l|}{201} \\
\hline REBEL & \multicolumn{2}{|l|}{26} & \multicolumn{2}{|l|}{36} & \multicolumn{2}{|l|}{159} & \multicolumn{2}{|l|}{221} \\
\hline $\begin{array}{l}\text { Average age in } \\
\text { years (range) }\end{array}$ & \multicolumn{2}{|c|}{$73.2(56-85)$} & \multicolumn{2}{|c|}{$75.6(57-92)$} & \multicolumn{2}{|c|}{$71.9(39-89)$} & \multicolumn{2}{|c|}{$72.6(39-92)$} \\
\hline Median age & \multicolumn{2}{|l|}{72} & \multicolumn{2}{|l|}{74} & \multicolumn{2}{|l|}{73} & \multicolumn{2}{|l|}{73} \\
\hline \multirow{2}{*}{$\begin{array}{l}\text { Indication for } \\
\text { REBEL }\end{array}$} & PAOD & PA & PAOD & PA & PAOD & PA & PAOD & PA \\
\hline & 21 & 5 & 33 & 3 & 119 & 40 & 173 & 48 \\
\hline Sex distribution & Females & Males & Females & Males & Females & Males & Females & Males \\
\hline Number (\%) & $8(30.8)$ & $\begin{array}{l}18 \\
(69.2)\end{array}$ & $\begin{array}{l}16 \\
(48.5)\end{array}$ & $\begin{array}{l}17 \\
(51.5)\end{array}$ & $\begin{array}{l}30 \\
(21.1)\end{array}$ & $\begin{array}{l}112 \\
(78.9)\end{array}$ & $\begin{array}{l}54 \\
(26.9)\end{array}$ & $\begin{array}{l}147 \\
(73.1)\end{array}$ \\
\hline \multicolumn{9}{|l|}{ Risk factors (\%) } \\
\hline DM & \multicolumn{2}{|l|}{7} & \multicolumn{2}{|l|}{12} & \multicolumn{2}{|l|}{64} & \multicolumn{2}{|c|}{$83(41.3 \%)$} \\
\hline Smoking & \multicolumn{2}{|l|}{15} & \multicolumn{2}{|l|}{14} & \multicolumn{2}{|l|}{68} & \multicolumn{2}{|c|}{97 (48.2\%) } \\
\hline CAD & \multicolumn{2}{|l|}{14} & \multicolumn{2}{|l|}{15} & \multicolumn{2}{|l|}{54} & \multicolumn{2}{|c|}{$83(41.3 \%)$} \\
\hline Hypertension & \multicolumn{2}{|l|}{24} & \multicolumn{2}{|l|}{31} & \multicolumn{2}{|l|}{123} & 178 (88. & \\
\hline RI & 8 & & 10 & & 39 & & $57\left(28.3^{c}\right.$ & \\
\hline Hyperlipidaemia & 18 & & 24 & & 92 & & 134 & \\
\hline
\end{tabular}

REBEL: revascularization of below knee arteries

PGN: prosthetic graft without MOD

PGY: prosthetic graft with modification of the distal anastomosis (MOD)

VG: autogenous venous graft REBEL

PAOD: peripheral arterial occlusive disease

PA: peripheral aneurysms

DM: Diabetes mellitus 
CAD: Coronary artery disease

Rl: Renal insufficiency

Intraoperative details (Table 2):

The reasons for opting for a prosthetic graft $(n=62)$ were; small vein caliber $<3 \mathrm{~mm}(n=30)$, vein already harvested for a peripheral $(n=23)$ or coronary bypass $(n=7)$ surgery or varicose veins $(n=2)$. Venous grafts were used in both reversed $(n=147 / 159)$ and non-reversed $(12 / 159)$ techniques. MOD in the PGY group are depicted in Fig. 1. Kruskal-Wallis-Test showed a significant difference $(p=0.001)$ in the distribution of operative time for the three groups. PGN group had significantly higher number of REBEL with operative time $<180$ mins and lower number of REBELs with operative time $>300$ mins as compared to the PGY group (Pearson-chi2 Test $p=0.015)$. This is in coherence with expectations that revascularization with venous graft and MOD would be more time consuming.

Table 2: Intraoperative details. 


\begin{tabular}{|c|c|c|c|}
\hline Segment for proximal anastomosis & PGN $(n=26)$ & $\operatorname{PGY}(n=36)$ & $V G(n=159)$ \\
\hline External iliac A. (\%) & - & $1(2.8)$ & - \\
\hline Common femoral A. (\%) & $17(65)$ & $28(77.8)$ & $75(47.2)$ \\
\hline Superficial femoral A. (\%) & $4(15.4)$ & $2(5.6)$ & $25(15.7)$ \\
\hline Deep femoral A. (\%) & $1(3.8)$ & $3(8.3)$ & $6(3.8)$ \\
\hline Popliteal A. (P1) (\%) & $4(15.4)$ & $1(2.8)$ & $37(23.3)$ \\
\hline Popliteal A. (P3) (\%) & - & - & $14(8.8)$ \\
\hline Crural Arteries (\%) & - & $1(2.8)$ & $2(1.2)$ \\
\hline \multicolumn{4}{|l|}{-} \\
\hline \multicolumn{4}{|l|}{ Segment for distal anastomosis } \\
\hline Popliteal A. (P3) (\%) & $18(69.2)$ & $8(22.2)$ & $68(42.8)$ \\
\hline Crural Arteries (\%) & $8(30.8)$ & $28(77.8)$ & $83(52.2)$ \\
\hline Dorsalis pedis A. (\%) & - & - & $8(5)$ \\
\hline \multicolumn{4}{|l|}{ Graft characteristics. } \\
\hline Hb-ePTFE (\%) & $25(96.2)$ & $32(89)$ & - \\
\hline Omniflow $^{\circledR}(\%)$ & $1(3.8)$ & $4(11)$ & - \\
\hline GSV (\%) & - & - & $146(91.8)$ \\
\hline SSV (\%) & - & - & $2(1.3)$ \\
\hline$\geq 2$ Veins & - & - & $11(6.9)$ \\
\hline \multicolumn{4}{|l|}{-} \\
\hline \multicolumn{4}{|l|}{ Operative Time } \\
\hline Average time in mins (range) & $212(117-391)$ & $284(178-502)$ & $285(131-642)$ \\
\hline Median time in mins & 209 & 265 & 262 \\
\hline$<180$ mins $(n)$ & 8 & 2 & 17 \\
\hline $180-300$ mins $(n)$ & 13 & 18 & 91 \\
\hline$>300$ mins $(n)$ & 5 & 16 & 51 \\
\hline
\end{tabular}


PGN: prosthetic graft without MOD

PGY: prosthetic graft with modification of the distal anastomosis (MOD)

VG: autogenous venous graft REBEL

REBEL: revascularization of below knee arteries

Hb-ePTFE: Heparin-bonded expanded polytetrafluoroethylene grafts

GSV: Great saphenous vein

SSV: Small saphenous vein

Mins: minutes

Postoperative results:

All the patients belonging to the PGN und PGY group were prescribed postoperative antiplatelet drugs (AP). Only 12 patients in the VG didn't receive any AP but these patients received oral anticoagulants (OAK). $55.6 \%$ of patients $(n=20 / 36)$ in the PGY group received a combination of AP and OAK. This was significantly higher $(p=0.05)$ as compared to the PGN $(n=8 / 26)$ and the VG $(n=53 / 159)$ group. Log-ranktest showed no significant difference regarding the primary patency, the assisted patency rates and the cumulative survival between the 3 groups (Fig. 2, Table 3, Supplemental Fig. 1) at 12 and 36 months. Comparison of the three groups in reference to secondary patency rate at 36 months, revealed a p-value of 0,058 . However, paired-log-rank test showed a significant difference in the secondary patency rates (Fig. 3 ) between the VG and PGY ( $p=0,017)$ group but this was insignificant $(p=0,316)$ between the PGN and PGY group. There was a significant difference in the amputation free survival between the three groups at 48 months (Log-rank-test $p<0.001$ ) (Fig. 3). The patients in PGY group showed significantly inferior amputation free survival as compared to VG and PGN at 48 months $(p<0,001$ and $p=0,038)$. 
Table 3

Patency rates and survival rates in patients undergoing REBEL (in months):

\begin{tabular}{|lccccc|}
\hline Months & 1 & 12 & 24 & 36 & 48 \\
\hline \multicolumn{7}{|c|}{ Primary patency rates (\%) } \\
\hline PGN & 88.1 & 74.2 & 50.1 & 50.1 & 50.1 \\
\hline PGY & 91.4 & 50.1 & 46.1 & 36.9 & - \\
\hline VG & 95.1 & 64.6 & 56.1 & 51.4 & 49.0 \\
\hline Assisted primary patency rates (\%) & \\
\hline PGN & 88.1 & 74.2 & 50.1 & 50.1 & 50.1 \\
\hline PGY & 91.4 & 53.2 & 49.4 & 39.5 & - \\
\hline VG & 95.1 & 70.4 & 64.3 & 62.1 & 62.1 \\
\hline Secondary patency rates (\%) & & \\
\hline PGN & 88.1 & 78.5 & 59.6 & 59.6 & 59.6 \\
\hline PGY & 91.4 & 59.7 & 55.7 & 44.6 & - \\
\hline VG & 97.9 & 76.1 & 69.9 & 67.5 & 67.5 \\
\hline Amputation free survival (\%) & & \\
\hline PGN & 92 & 87.6 & 81.3 & 69.7 & 69.7 \\
\hline PGY & 95.3 & 62.9 & 54.3 & 43.4 & 43.4 \\
\hline VG & 97.3 & 89.8 & 87.1 & 86 & 86.0 \\
\hline Survival (\%) & & & & \\
\hline PGN & 88.5 & 64.8 & 60.7 & 50.5 & 50.5 \\
\hline PGY & 94.3 & 82.5 & 78.4 & 58.9 & 58.9 \\
\hline VG & 92.5 & 87.6 & 76 & 61.1 & 56.3 \\
\hline
\end{tabular}

REBEL: revascularization of below knee arteries

PGN: prosthetic graft without MOD

PGY: prosthetic graft with modification of the distal anastomosis (MOD)

VG: autogenous venous graft REBEL 


\section{Discussion:}

Despite advancements in the field of endovascular surgery, bypass surgery is an absolute essential part of vascular surgeons' armamentarium. Regardless the superiority of venous conduit $(3,4)$, prosthetic grafts are a viable alternative when the vein is disadvantageous (5), for e.g. in cases of small vein caliber, varicose veins or thrombophlebitis or unavailability because of previous harvesting for coronary or peripheral bypass (6). The initial results of infrapopliteal revascularizations with prosthetic grafts were poor as compared to venous conduits $(7,8,9)$. Several strategies have been utilized to improve the performance and patency of prosthetic grafts. Some of these are: venous modifications of the distal anastomosis (MOD) $(10,11,12,5)$, heparin bonding at the luminal surface of PTFE grafts (Hb-ePTFE, Propaten; W.L. Gore \& Associates, Inc.) $(13,14)$, distal AV-fistula (15) and grafts reinforced with rings (16).

MOD are advantageous in decreasing the intimal hyperplasia (17), by improving the flow characteristics (18) and reducing compliance-mismatch and shear stress (19) between relatively rigid prosthetic graft and undersized, delicate, calcified crural vessels. Experimental studies show that the intimal hyperplasia is most prominent at the transition between graft and MOD and least at the recipient artery (20). This spares the artery in an acceptable state for a redo revascularization and may further improve the secondary patency rates (12). The classical MOD were improved with time $(21,22)$. A boot shaped modification was described in 2000 and was known as St. Mary's boot (23). The distal vein patch technique (DVPT) showed acceptable long-term results in a series published by Neville et al. (11). We performed the St. Mary's boot (Supplemental Fig. 2). and the DVPT in 14 and 15 cases respectively. Holdsworth et al. (24) proposed a composite graft, where a segment of an autologous vein is anastomosed to a prosthetic graft and used for the distal anastomosis. We performed this technique in 4 patients. Bridged Bypass technique to improve the distal run-off and the compliance-mismatch was resorted to in 3 patients (25).

The median follow-up of 27 months was comparable to studies conducted by Daenens et al. and Pulli et al. $(26,27)$. The three groups (PGN, PGY and VG) in this study were comparable in terms of age $(p=$ $0,271)$ and comorbidities. PGN and VG had significantly higher number of male patients. The most common risk factors were Hyperlipidaemia and Hypertension $(28,12)$. In $94.5 \%$ of patients' critical limb ischemia was the indication for REBEL. In SCAMICOS (29) pre-existing cardiac illness and previous vascular surgery were the most common risk factors and $94 \%$ patients suffered from either rest pain or ulcer or gangrene. In our study out of 48 aneurysm-patients, 25 were asymptomatic. Venous conduit for REBEL was used in $83 \%(n=40 / 48)$ aneurysm-patients. In 50\% $(n=17 / 36)$ of patients in PGY group, the vein had already been harvested for a peripheral reconstruction. This was $20 \%(n=5 / 26)$ in the PGN group. This difference was not significant $(p=0,066)$ but indicates that more patients in PGY had already undergone previous peripheral bypass surgery. The most common site of distal anastomosis in PGN group was the P3 segment of poplitea artery (69\%) and in PGY group the crural arteries (77\%). This significant difference $(p=0.002)$ suggests that PGY group patients the P3 segment was not adequate for distal anastomosis. This may have been because of previous surgery and/or stenting and/or occlusion 
due to diseased vessel. In 112 tibial bypass procedures presented by Neville et al (28), the patients with prosthetic graft bypass had a higher rate of prior bypass surgery.

The time taken to accomplish REBEL in PGY group was significantly more $(p=0,015)$ as compared to PGN group. Average duration of REBEL in PGY group was 284 minutes, comparable to VG group (average duration 285mins) but 72 minutes more as compared to the average for PGN group $(p=0.001)$. The decision regarding the postoperative antithrombotic therapy was not standardized in our study and was dependent on surgeons' preference, distal outflow, patients' comorbidities and type of revascularization performed. More than $50 \%$ of patients in the PGY group received a combination of AP and OAK. This was significantly higher $(p=0.05)$ as compared to the both PGN and VG group. Daenens et al $(26)$ administered $160 \mathrm{mg}$ of aspirin per day in the postoperative period. Warfarin anticoagulation was only given to patients who received it preoperatively and in redo venous bypass patients.

The patency rates can be compared with the help of Kaplan-meier plots (Fig. 2,3). The primary patency rates for PGY vs PGN were $50 \%$ vs $74.2 \%$ at 12 months and $36.9 \%$ vs $50.1 \%$ at 36 months respectively. A similar trend was observed with the assisted primary patency rates. The difference between the PGY and PGN group for both primary patency $(p=0,226)$ and assisted primary patency $(p=0.74)$ was not significant. This may have been because of the relatively lower number of patients. A meta-analysis conducted by Albers et al (9) revealed pooled 1- and 2-year primary patency rates of $59 \%$ and $48 \%$, respectively, for standard ePTFE grafts used in infrapopliteal procedures. Neville et al. (28) performed 62 femoro-crural reconstructions with Hb-ePTFE and distal vein patch and reported a 1-year primary patency of $75.4 \%$, as compared to $86 \%$ for venous grafts. The primary, assisted primary and secondary patency rates at 12 and 36 months for PGN group were comparable to VG (Table 3). The secondary patency rates at 12 and 36 months in PGY group were significantly inferior as compared to VG $(59.7 \%$ vs $76.1 \%$ and $44.6 \%$ vs $67.5 \% ; p=0.017$ ) but were relatively inferior, even though not significant as compared to PGN group $(59.7 \%$ vs $78.5 \%$ and $44.6 \%$ vs $59.6 \% ; p=0.0316)$. A significantly higher rate of amputation was observed in the PGY group. Amputation-free Survival in PGY group was significantly lower at 12 (62.9\% vs $87.6 \% ; p=0.038)$ and at 48 months $(43.4 \%$ vs $69.75 \% ; p<0.001)$ as compared to the PGN group. The three groups didn't show any significant difference $(p=0.375)$ in overall survival (Table 3 , Supplemental Fig. 1 ). In SCAMICOS (29) the primary patency at 36 months was $26 \%$ with MOD and $43 \%$ without MOD in femoro-popliteal reconstructions and $20 \%$ and $17 \%$ for femoro-crural reconstructions respectively. The amputation-free survival was better for the revascularizations with MOD both for femoro-popliteal and femoro-crural revascularizations, but this was not statistically significant. Similar to our study, the SCAMICOS (29) could not demonstrate any benefit of MOD for below knee revascularizations with PTFE. A meta-analysis (30) published in 2012 involving 885 patients with below-knee popliteal and crural bypasses. This metanalysis showed no significant improvement for primary patency or limb survival at 3 years for femoro-crural bypasses with venous cuff. In our study, we achieved good patency rates at 1 month (Table 3) for all three groups. These were better for the PGY group as compared to PGN, even though this was not statistically significant. This is an evidence of technical success and expertise of our surgeons. These findings are also in coherence with the reanalysis in the SCAMICOS cohort (31). 
Keeping the abovementioned results in mind, we would like to indicate towards the fact that the patients undergoing REBEL with MOD suffer from advanced PAD with prior single or multiple revascularizations (surgical or endovascular). The surgery was more time consuming because of the site of distal anastomosis, possible dissection of the fine crural arteries, vein harvesting and MOD. Because of the poor limb salvage rates, patients undergoing REBEL with MOD would require anticoagulation in addition to AP and demand exhaustive perioperative vascular surgical care, monitoring and decision making.

\section{Limitations Of The Study:}

In view of aforementioned results, it is difficult to interpret if MOD offer a significant improvement in the patency rates, survival or extremity salvage as compared to revascularizations with prosthetic grafts without MOD, counterwise the patients in PGY group were associated with higher amputation rates. Because of the retrospective and non-randomized design of the study, the three groups were not matched with respect to; the site of distal anastomosis and prior vascular surgeries or interventions. These factors posed a significant difference between PGN and PGY. The question if MOD is advantageous and offers better patency rates and survival can't be answered until these confounding factors are matched. This study doesn't document the outflow vessels after bypass surgery, which is an important factor in predicting the patency rates (32). A prospective, randomized study with more patients should be able to shed light on this question.

\section{Conclusion:}

For revascularization of below knee arteries (REBEL), autologous vein is the conduit of choice. In the absence or unsuitability of the vein, prosthetic grafts are recommendable. In the present study, adding a venous modification to the distal anastomosis failed to improve the performance of the prosthetic grafts and offered no advantage in terms of patency or amputation prevention. Surgery in PGY was more time consuming and most common site of distal anastomosis were the crural arteries. Significantly more patients with previous peripheral revascularization surgeries suggests that patients in PGY suffered from advanced PAOD. Nevertheless, in view of the technical difficulties to surgically anastomose a comparatively rigid, large caliber prosthetic graft to a delicate crural artery and flow-improving advantages of $\operatorname{MOD}(15,33)$, lower extremity revascularization in crural region with prosthetic grafts should be performed with MOD.

\section{Abbreviations}

REBEL: Peripheral revascularization with below-knee bypass

MOD: Venous modifications of the distal anastomosis

PGY: Prosthetic Graft with venous modifications (Peripheral revascularization with below-knee bypass using prosthetic graft with venous modification of the distal anastomosis 
PGN: Prosthetic Graft without venous modifications (Peripheral revascularization with below-knee bypass using prosthetic graft without venous modification of the distal anastomosis

VG: Venous graft (Peripheral revascularization with below-knee bypass using venous conduit)

PAOD: Peripheral arterial occlusive disease

SFA: Superficial femoral artery

GSV: Greater saphenous vein

PA: Peripheral aneurysms

DM: Diabetes mellitus

CAD: Coronary artery disease

Rl: Renal insufficiency

DVPT: distal vein patch technique

AP: Antiplatelet drugs

OAK: Oral anticoagulants

PTFE: Polytetrafluoroethylene

Hb-ePTFE: Heparin bonded Polytetrafluoroethylene

SSV: Small saphenous vein

\section{Declarations}

\section{Ethics approval and consent to participate:}

The study was approved by the ethics committee of the medical council in Hessen.

\section{Statement of informed consent:}

A written consent was obtained from all patients or their legal representatives before enrolment into the study.

\section{Availability of data and materials:}

The datasets used and/or analysed during the current study are available from the corresponding author on reasonable request. 


\section{Competing Interests:}

The authors declare that they have no competing interests.

Funding: None

Disclosure: Nothing to disclose

\section{Author contributions:}

Conceiving and designing the study: AF, PS, PK

Collecting the data: AF, PS, PK

Analyzing and interpretation the data: AS, OY, AF, PS, PK

Writing the manuscript: AS, OY, AF

Statistical Analysis: AF, PS, AS, PK

Critical Revisions of the article: AS, OY, AF, PS, PK

Final approval of the article: AS, OY, AF, PS, PK

Overall responsibility: AS, OY, AF, PS, PK.

Acknowledgement: Not applicable

\section{References}

1. Menzoian JO, Koshar AL, Rodrigues N. Alexis Carrel, Rene Leriche, Jean Kunlin, and the history of bypass surgery. J Vasc Surg. 2011;54:571-574

2. Balletshofer, B., Ito, W., Lawall, H. et al. Positionspapier zur Diagnostik und Therapie der peripheren arteriellen Verschlusskrankheit (pAVK) bei Menschen mit Diabetes mellitus. Diabetologe. 2020;16:65-73

3. Ambler GK, Twine CP. Graft type for femoro-popliteal bypass surgery. Cochrane Database of Systematic Reviews 2018;2:Art. No.: CD001487

4. Pereira CE, Albers M, Romiti M et al. Meta-analysis of femoropopliteal bypass grafts for lower extremity arterial insufficiency, Journal of Vascular Surgery. 2006;44,3:510-517

5. Aracil-Sanus E, et al. Infragenicular Bypass Graft for Limb Salvage Using Polytetrafluoroethylene and Distal Vein Cuff as the First Alternative in Patients Without Ipsilateral Greater Saphenous Vein. Ann Vasc Surg. 2005;19:1-7.

6. Chew DK, Owens CD, Belkin M et al. Bypass in the absence of ipsilateral greater saphenous vein: safety and superiority of the contralateral greater saphenous vein. J Vasc Surg. Jun. 
2002;35(6):1085-92

7. Whittemore $A D$, Kent KC, Donaldson $M C$ et al. What is the proper role of polytetrafluoroethylene grafts in infrainguinal reconstruction? J Vasc Surg. 1989 Sep;10(3):299-305.

8. Londrey GL, Ramsey DE, Hodgson KJ et al. Infrapopliteal bypass for severe ischemia: comparison of autogenous vein, composite, and prosthetic grafts. J Vasc Surg. 1991 May;13(5):631-6.

9. Albers $M$, Battistella VM, Romiti $M$ et al. Meta-analysis of polytetrafluoroethylene bypass grafts to infrapopliteal arteries. J Vasc Surg. 2003; 37:1263-1269

10. Neville RF, Sidaway AN. Myointimal hyperplasia: basic science and clinical considerations. Semin Vasc Surg. 1998; 28:143-148

11. Neville RF, Lidsky M, Capone A et al. An expanded series of distal bypass using the distal vein patch technique to improve prosthetic graft performance in critical limb ischemia. Eur $\mathrm{J}$ Vasc Endovasc Surg. 2012;44:177-182

12. Raptis S, Miller JH. Influence of a vein cuff on polytetrafluoroethylene grafts for primary femoropopliteal bypass. Br J Surg. 1995;82:487-491

13. Lindholt JS, Gottschalksen B, Johannesen N et al. The Scandinavian Propaten( $(\circledR)$ trial - 1-year patency of PTFE vascular prostheses with heparin-bonded luminal surfaces compared to ordinary pure PTFE vascular prostheses - a randomized clinical controlled multi-centre trial. Eur J Vasc Endovasc Surg. 2011 May;41(5):668-673

14. Dorigo W, et al. Results from an Italian multicentric registry comparing heparin bonded ePTFE graft and autologous saphenous vein in below-knee femoro-popliteal bypasses. J Cardiovasc Surg (Torino). 2012;53(2):187-194

15. Kreienberg PB, Darling RC III, Chang BB et al. Adjunctive techniques to improve patency of distal prosthetic bypass grafts: polytetrafluoroethylene with remote arteriovenous fistulae versus vein cuffs. J Vasc Surg. 2000; 31:696-701

16. Debus ES, Diener H, Larena-Avellaneda A. Postoperative Komplikationen in der Gefäßchirurgie. Chirurg. 2009;80:814-26

17. Kissin M, Kansal N, Pappas PJ et al. Vein interposition cuffs decrease the intimal hyperplasia response of polytetrafluoroethylene bypass grafts. J Vasc Surg. 2000;31:69-83

18. Beard JD, Benveniste GL, Miller JH et al. Hemodynamics of the interposition vein cuff. Br J Surg. 1986 Oct;73(10):823-825

19. How TV, Rowe CS, Gilling-Smith GL et al. Interposition vein cuff anastomosis alters wall shear stress distribution in the recipient artery. J Vasc Surg. 2000;31(5):1008-1017

20. Trubel W, Schima H, Czerny M et al. Experimental comparison of four methods of end-to-side anastomosis with expanded polytetrafluoroethylene. Br J Surg. 2004;91:159-167

21. Miller JH, Foreman RK, Ferguson L et al. Interposition vein cuff for anastomosis of prosthesis to small artery. Aust N Z J Surg. 1984 Jun;54(3):283-285 
22. Taylor RS, Loh A, McFarland RJ et al. Improved technique for polytetrafluoroethylene bypass grafting: long-term results using anastomotic vein patches. Br J Surg. 1992;79:348-54.

23. Smout JD, Wolfe JH. Venous boot construction for a distal prosthetic bypass. Semin Vasc Surg. 2000;13:53-57

24. Holdsworth PJ, Riddell PS, Leveson SH. Distal femoropopliteal bypass using a composite graft of PTFE and non-reversed saphenous vein. Ann R Coll Surg Engl. 1989;71(1):4-6

25. Deutsch $\mathrm{M}$, Meinhart J, Howanietz $\mathrm{N}$ et al. The bridge graft: a new concept for infrapopliteal surgery. Eur J Vasc Endovasc Surg. 2001 Jun;21(6):508-512

26. Daenens K, Schepers S, Fourneau I et al. Heparin- bonded ePTFE grafts compared with vein grafts in femoropopliteal and femorocrural bypasses: 1- and 2-year results. J Vasc Surg. 2009;49:1210-1216 27 Pulli R, Dorigo W, Castelli $P$ et al. Midterm results from a multicenter registry on the treatment of infrainguinal critical limb ischemia using a heparin-bonded ePTFE graft. J Vasc Surg. 2010;51:11671177

27. Neville RF, Capone A, Amdur R et al. A comparison of tibial artery bypass performed with heparinbonded expanded polytetrafluoroethylene and great saphenous vein to treat critical limb ischemia. $J$ Vasc Surg. 2012;56:1008-1014

28. Lundgren F. Scandinavian Miller Collar Study (SCAMICOS). PTFE Bypass to Below-knee Arteries: Distal Vein Collar or Not? A Prospective Randomized Multicenter Study. Eur J Vasc Endovasc Surg. 2010;39:747-54.

29. Twine CP, Williams IM und Fligelstone LJ. Systematic review and meta- analysis of vein cuffs for below-knee synthetic bypass. British Journal of Surgery. 2012;99:1195-1202

30. Lundgren F. The vein collar: an anastomotic servant or a patency promoter? Re-analysis of a randomized trial. Int Angiol. 2012 Jun;31(3):234-238

31. Conte MS, Belkin M, Upchurch GR et al. Impact of increasing comorbidity on infrainguinal reconstruction: a 20-year perspective. Ann Surg. 2001;233:445-452

32. Moawad J und Gagne P. Adjuncts to Improve Patency of Infrainguinal Prosthetic Bypass Grafts. Vasc Endovasc Surg. 2003;37:381-6

\section{Figures}




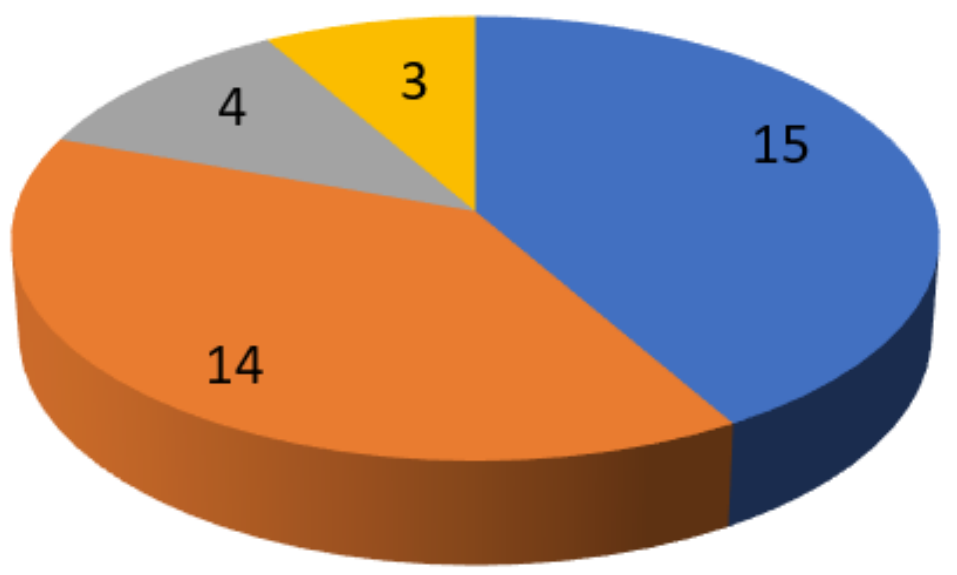

- Linton's Patch (41.7\%)

St. Mary's Boot

(38.9\%)

Composite Bypass

(11.1\%)

Bridged vein (8.3\%)

\section{Figure 1}

Distribution of type of Venous modifications of distal anastomosis (MOD).
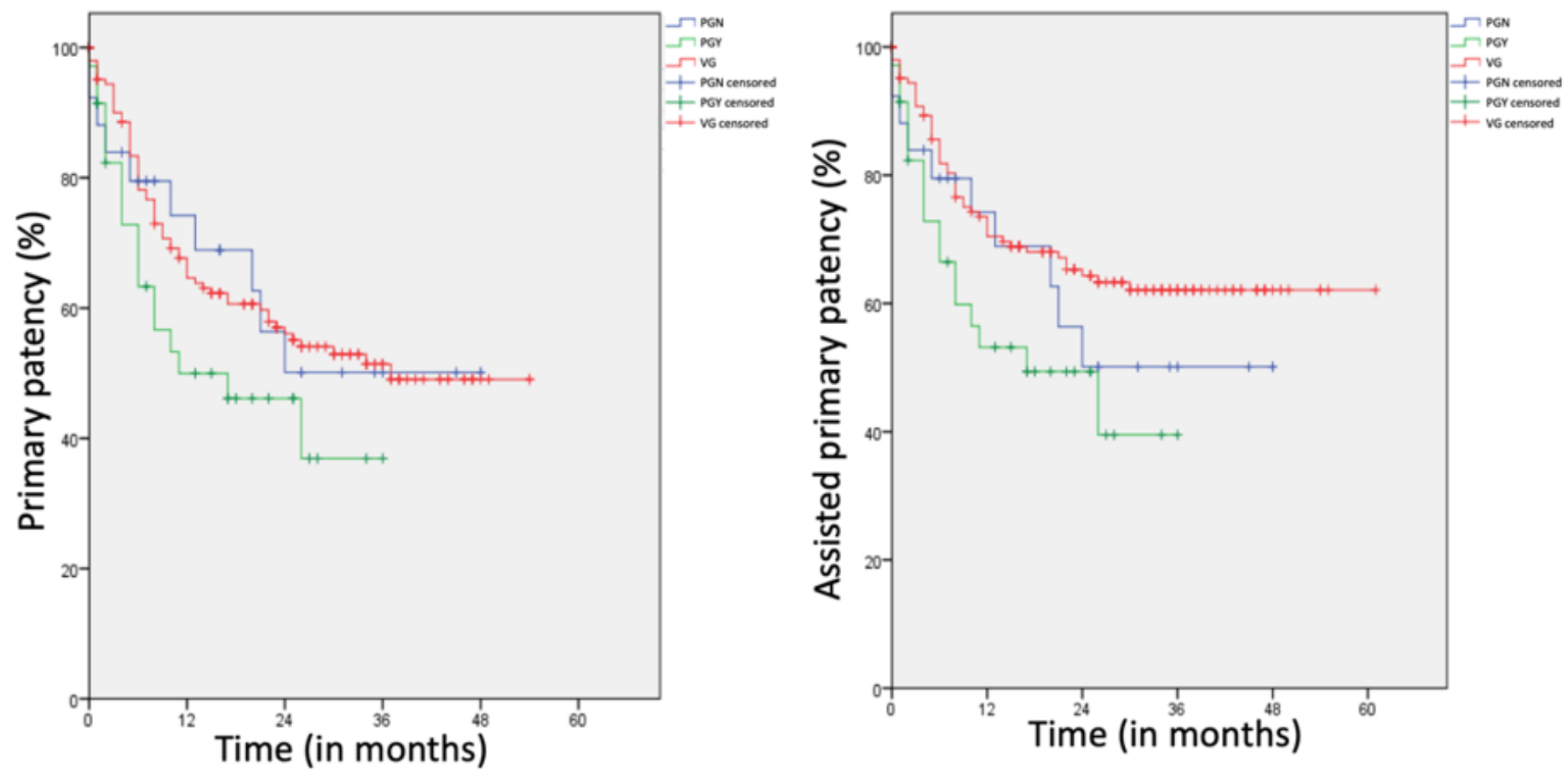
Figure 2

Kaplan-meier plots. No significant difference for primary patency $(p=0.226$; left) and assisted primary patency $(p=0.074$; right) between the three groups.
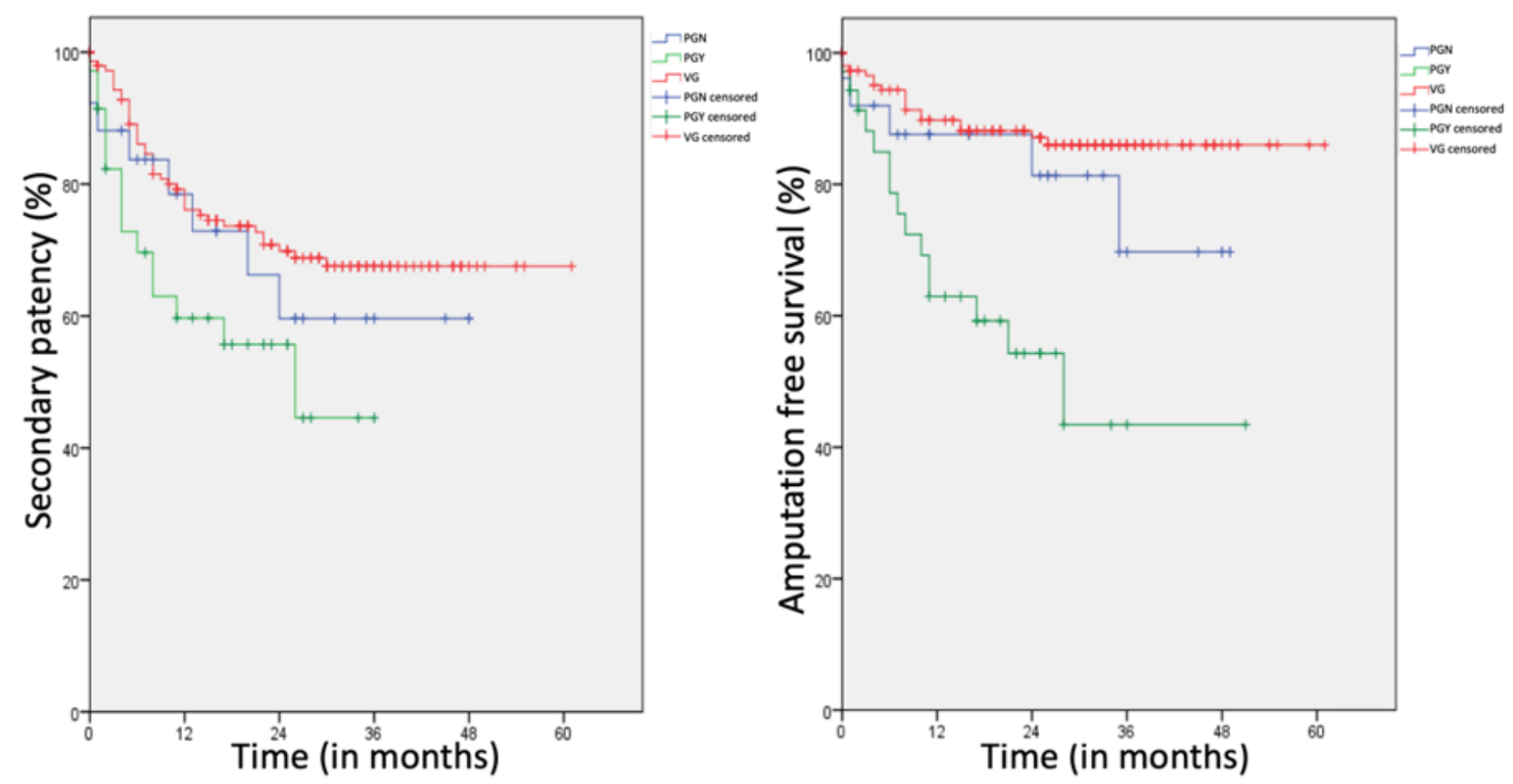

Figure 3

left: Kaplan-meier plots for secondary patency. Significant difference $(p=0.017)$ between VG and PGY but no significant between PGY and PGN ( $p=0.316)$ right: Kaplan-meier plots for amputation free survival. Significant difference between the three groups $(p<0.001)$.

\section{Supplementary Files}

This is a list of supplementary files associated with this preprint. Click to download.

- JOTSSupplementalFig1.docx

- JOTSSupplementalFig2.docx 